\title{
Quality of food choices of Brazilian adolescents according to individual earnings
}

\author{
Marina Campos Araujo ${ }^{1, *}$, Diana Barbosa Cunha ${ }^{2}$, llana Nogueira Bezerra ${ }^{3}$, \\ Maria Beatriz Trindade de Castro $^{4}$ and Rosely Sichieri ${ }^{2}$ \\ ${ }^{1}$ Sergio Arouca National School of Public Health, Oswaldo Cruz Foundation/Ministry of Health, Rua Leopoldo \\ Bulhões 1480, sala 803, Bonsucesso, 21041-210 Rio de Janeiro, RJ, Brazil: ${ }^{2}$ Department of Epidemiology, Social \\ Medicine Institute, State University of Rio de Janeiro, Rio de Janeiro, RJ, Brazil: ${ }^{3}$ Ceará State University, Master in \\ Nutrition and Health Course, Fortaleza, CE, Brazil: ${ }^{4}$ Institute of Nutrition Josué de Castro, Federal University of Rio de \\ Janeiro, Nutritional Observatory of Epidemiology, Department of Social and Applied Nutrition, Rio de Janeiro, RJ, Brazil
}

Submitted 30 November 2016: Final revision received 5 June 2017: Accepted 7 July 2017: First published online 30 August 2017

\begin{abstract}
Objective: To evaluate the quality of food choices according to adolescent individual earnings in Brazil.

Design: Adolescents were classified according to their individual earnings as having or not having spending power for their own expenses. Food records from two non-consecutive days of the Brazilian National Dietary Survey (NDS 2008-2009) were used to estimate food intake. Quality of food choices was based on two approaches: (i) the NOVA classification, which classifies processed and ultra-processed foods and drinks as unhealthy food groups; and (ii) traditional classification, with beans, milk, fruits and vegetables as healthy food groups, and soft drinks, sweets, snacks and crackers classified as unhealthy. We compared mean food intake $(\mathrm{g} / \mathrm{kJ}$ or $\mathrm{ml} / \mathrm{kJ})$ according to per capita household income (tertiles) and adolescent individual earnings, with adolescent earnings adjusted for household income, using multiple linear regression.

Setting: Brazilian households ( $n$ 13 569).

Subjects: Adolescents aged 14-18 years ( $n$ 3673).

Results: Males without individual earnings had higher per capita household income than those with individual earnings. Household income was associated with all three food groups of the NOVA classification and seven of the eight groups of the traditional classification. However, only beans and snacks were consumed in significantly greater quantities by adolescents with individual earnings compared with those without earnings.

Conclusions: Adolescent individual earnings were not the main driver of food choices; however, per capita household income was associated with food choices. The consumption of both healthy and unhealthy items increased with increasing household income.
\end{abstract}

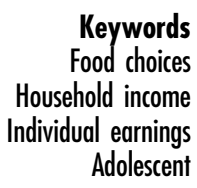

Brazilian adolescent diets comprise a mix of traditional foods, such as rice and beans, and ultra-processed foods including mainly sugar-sweetened beverages ${ }^{(1)}$. This is a high-energy, low-quality diet and has been associated with a high prevalence of inadequate nutrient intake ${ }^{(2)}$. The diet characteristics may be promoting the increase in obesity prevalence in Brazil where one in five Brazilian adolescents is overweight or obese ${ }^{(3)}$, which can result in immediate and long-term harmful health outcomes ${ }^{(4-6)}$.

It is well known that adolescence is marked by important physical, psychological, sociocultural and cognitive changes, which are reflected in independence and autonomy from $\operatorname{adults}^{(7,8)}$. An important consequence of this process is the increasing independence in adolescents' food choices ${ }^{(9)}$ and decreasing resemblance of dietary intake between parent and child over time ${ }^{(10)}$, especially among higher socioeconomic levels. A population-based survey conducted in the city of Rio de Janeiro, Brazil, examined the correlation between the food intake of adolescents and their parents according to socio-economic variables. The survey observed lower correlation in food intake between mothers and adolescents of higher socio-economic levels ${ }^{(11)}$.

Furthermore, Brazil has experienced a rapid economic growth in the last decade, reducing poverty and inequality rates, which may reflect on adolescents' individual earnings and ability to pay for a variety of items, including food. 
This situation provides an opportunity to examine more carefully how purchasing power affects unhealthy food choices by adolescents. To describe disparities in food choices across different social groups, the present study evaluated whether Brazilian adolescents with individual earnings consume more unhealthy foods than those without financial autonomy.

\section{Methods}

\section{Population}

The present study analysed data obtained from the Brazilian National Dietary Survey (NDS), which was carried out along with the 2008-2009 Household Budget Survey (HBS) conducted by the Brazilian Institute of Geography and Statistics. The Brazilian HBS sample was selected using a two-stage cluster sampling design. In the first stage, census tracts (the primary sampling units) were selected by systematic sampling with probability proportional to the number of households. Census tracts were stratified to include representatives of all Brazilian regions, including both urban and rural areas and different socioeconomic levels. The households were selected in the second stage by simple random sampling. The 2008-2009 HBS included 4694 census tracts with 68373 households. The interviews were conducted on 55970 households and 190159 residents from all ages and both genders were investigated. A sub-sample of $25 \%$ of the HBS was estimated to participate in the NDS. Finally, 13569 households agreed to participate in the survey (21\% were non-responders). Individuals aged 10 years or older ( $n$ 34 003) living in the selected households were included in the dietary survey. In the current paper, we included only adolescents aged $14-18$ years ( $n$ 3855). A total of 139 pregnant women and forty-three adolescents who did not answer the income question were excluded from analysis, yielding a final sample of 3673 Brazilian adolescents $^{(12)}$.

\section{Data collection}

Food records from two non-consecutive days were used to estimate food intake. The two food records were obtained within one week on non-consecutive days. All respondents reported all foods and drinks consumed, amounts, time and place of meals (at home or away from home). Individuals received a booklet with explanations on how to fill in the records and with pictures of tableware to help them to estimate the amount of food consumed. Trained interviewers were responsible for reviewing all records before entering the data in a data entry program specially designed for the survey. This program contained approximately 1500 items (foods and drinks), fourteen types of food preparation and 106 portion sizes. Details about the pre-test, training and validation of the food records have been published elsewhere ${ }^{(12)}$.
Body weight was measured by trained interviewers using a portable electronic scale with capacity of $150 \mathrm{~kg}$ and height was assessed using a portable stadiometer. BMI was calculated, and the WHO AnthroPlus software based on WHO adolescent-specific BMI reference and classification was used ${ }^{(13)}$.

Monthly per capita household income from all monetary and non-monetary sources was calculated. The total household income was divided by the number of members in the household to calculate the per capita household income and then classified into tertiles: T1, $\leq$ \$US 103.4; T2, > \$US 103.4-223.5; T3, > \$US 223.5. The conversion rate at the time of the HBS (\$US $1=2.38$ Brazilian Real) was applied to convert the amounts to US dollars. Moreover, the official minimum monthly wage in Brazil during this period was \$US 174.40.

Adolescents were classified according to their individual earnings as having or not having spending power for their own expenses. Adolescents were considered as having individual earnings if they received any kind of remuneration, from either a formal or informal job, and/or reported own expenses during one-week period. We did not include adolescents aged 13 years or younger since it is forbidden to work at this age in Brazil, even in informal jobs.

\section{Data analyses}

More than 2000 food items with their respective food preparation were reported. Food items were classified into mutually exclusive food groups using two approaches. One of the classifications (NOVA) is the current Brazilian Dietary Guideline $^{(14)}$, which is based on the extent and purpose of food processing. According to NOVA, foods/drinks were classified into four groups: (i) unprocessed or minimally processed foods (e.g. seeds, fruits, leaves, stems, roots, muscle, offal, eggs, milk); (ii) processed culinary ingredients (e.g. salt, sugar, honey, vegetable oils, butter); (iii) processed foods (e.g. salted or sugared nuts and seeds; salted, cured or smoked meats; canned fish; fruits in syrup; cheeses; and unpackaged freshly made breads); and (iv) ultra-processed foods and drinks (e.g. carbonated drinks, sweet or savoury packaged snacks, ice cream, chocolate, candies, margarines, cookies, cakes) ${ }^{(15)}$. For analyses, unprocessed or minimally processed foods and processed culinary ingredients were combined in the same group, named 'culinary preparations'. Second, we used the traditional food group classification used in the Brazilian $\operatorname{NDS}^{(12)}$. This classification is based on similarity of foods' nutrient composition, in which foods are grouped according to the key nutrient. For example, the key nutrients of milk and dairy products group include calcium and protein, while the fruit group is a good source of vitamins, especially vitamin C. Recipes were classified according to the main recipe ingredient. Eight food groups were considered: (i) beans and legumes (including preparations based on beans, such as feijoada); (ii) vegetables (raw, cooked and 
fried vegetables); (iii) fruit (raw, cooked and fried fruits excluding fruit-based desserts); (iv) milk and dairy products (excluding cheese and milk-based desserts); (v) sweets (cakes, cookies, fruit-based desserts and milk-based desserts); (vi) crackers (savoury snacks such as potato chips, corn chips, bacon chips and salty crackers); (vii) snacks (baked and deep-fried snacks, such as croquette, fried codfish cakes, fried pies, chicken nuggets and pizza); and (viii) soft drinks. Beans and legumes, vegetables, fruit and milk and dairy products were considered healthy food groups, while sweets, crackers, snacks and soft drinks were considered unhealthy food groups.

Food intake was based on the mean of two food records. Three per cent of adolescents ( $n$ 126) reported only one day of the food record and were excluded from this analysis. We compared the mean intake of each food group (g or $\mathrm{ml} / 4184 \mathrm{~kJ}(1000 \mathrm{kcal})$ ) using both approaches of food group classification according to monthly per capita household income tertiles. We compared food choices of adolescents with and without individual earnings adjusted for per capita household income. Incomeadjusted mean of food group intake was estimated using multiple linear regression.

Weighted means were estimated using survey procedures in the statistical software package SAS release 9.3 (2011) taking account of the sample design effect.

\section{Results}

Males without individual earnings had higher per capita household income than those with individual earnings (\$US 250 (95\% CI 227, 273) v. \$US 199 (95\% CI 177, 221)). Considering our primary hypothesis that adolescents with individual earnings consumed more unhealthy foods than those without financial autonomy, we also tested whether adolescents with individual earnings were more overweight or obese than their counterparts. However, the prevalence of excessive weight was similar between males and females with and without individual earnings (Table 1).

Since the results of mean food intake according to household income and adolescent individual earnings were similar between genders (data not shown), the results were combined. The mean intakes of the three food groups according to the NOVA classification and of seven of the eight groups analysed according to the traditional classification were associated with household income tertile. However, only two items were associated with adolescent individual earnings.

Considering the NOVA classification, the mean intakes of processed foods and ultra-processed foods and drinks increased according to household income tertile, while the mean intake of culinary preparations decreased with increasing per capita income (all $P<0 \cdot 01$ ). For the traditional classification of food groups, except for crackers $(P=0 \cdot 11)$, the mean intakes of vegetables, fruits, milk, sweets, snacks and soft drinks (all $P<0.01$ ) increased with household income and the mean intake of beans $(P<0.01)$ decreased with increased income (Table 2).

The NOVA classification was not associated with adolescent individual earnings. For the traditional food group classification, only the mean intakes of beans $(P=0.02)$ and snacks $(P=0.02)$ were higher among adolescents with individual earnings than among those without individual earnings (Table 3).

\section{Discussion}

In this population-based sample of Brazilian adolescents, adolescents' financial autonomy showed intriguing results. The consumption of one marker of a healthy diet (beans) and one of an unhealthy diet (snacks) was higher among adolescents with individual earnings compared with their counterparts without individual earnings.

The higher consumption of snacks among adolescents with individual earnings indicates that adolescent financial autonomy could lead to unhealthy food choices. Moreover, snack intake showed the greatest difference in food consumption among extreme family income tertiles. Families in higher income strata consumed more than three times the amount of snacks compared with families in the lowest income level. Both findings showed that snack intake, marked by baked and deep-fried snacks, such as croquette, fried pies and pizza, was the most sensitive food group to family and adolescent individual income. In Brazil, most snack consumption takes place

Table 1 Mean per capita household income and prevalence of excessive weight $(95 \% \mathrm{Cl})$ according to adolescent individual earnings and sex. Brazil, 2008-2009 National Dietary Survey

\begin{tabular}{|c|c|c|c|c|c|c|c|c|}
\hline \multirow[b]{3}{*}{ Variable } & \multicolumn{4}{|c|}{ Males ( $n$ 1883) } & \multicolumn{4}{|c|}{ Females ( $n$ 1790) } \\
\hline & \multicolumn{2}{|c|}{$\begin{array}{l}\text { With individual } \\
\text { earnings }(n 633)\end{array}$} & \multicolumn{2}{|c|}{$\begin{array}{l}\text { Without individual } \\
\text { earnings ( } n \text { 1250) }\end{array}$} & \multicolumn{2}{|c|}{$\begin{array}{l}\text { With individual } \\
\text { earnings ( } n \text { 468) }\end{array}$} & \multicolumn{2}{|c|}{$\begin{array}{l}\text { Without individual } \\
\text { earnings }(n 1322)\end{array}$} \\
\hline & Mean & $95 \% \mathrm{Cl}$ & Mean & $95 \% \mathrm{Cl}$ & Mean & $95 \% \mathrm{Cl}$ & Mean & $95 \% \mathrm{Cl}$ \\
\hline Mean per capita household income (\$US) ${ }^{*}$ & 199 & 177,221 & 250 & 227,273 & 222 & 198,247 & 246 & 222,271 \\
\hline Excessive weight $(\%)$ & $16 \cdot 3$ & 11,22 & $21 \cdot 8$ & 18,25 & $17 \cdot 1$ & 13,21 & $16 \cdot 9$ & 14,20 \\
\hline
\end{tabular}

*\$US $1=2.38$ Brazilian Real. 
Table 2 Weighted mean food group intake (SE) by NOVA and traditional food group classifications according to monthly per capita household income tertiles. Brazil, 2008-2009 National Dietary Survey

\begin{tabular}{|c|c|c|c|c|c|c|c|c|}
\hline \multirow[b]{2}{*}{ Food group $(\mathrm{g} / \mathrm{kJ}$ or $\mathrm{ml} / \mathrm{kJ})$} & \multicolumn{2}{|c|}{$\mathrm{T}^{*}(n 1456)$} & \multicolumn{2}{|c|}{$\mathrm{T}^{*}(n$ 1201) } & \multicolumn{2}{|c|}{$\mathrm{T}^{*}(n 1016)$} & \multirow[b]{2}{*}{ Diff. (\%)† } & \multirow[b]{2}{*}{$P$ for trend } \\
\hline & Mean & SE & Mean & $\mathrm{SE}$ & Mean & SE & & \\
\hline \multicolumn{9}{|l|}{ NOVA classification } \\
\hline Culinary preparations $\ddagger$ & 691.8 & $6 \cdot 2$ & 664.5 & $5 \cdot 7$ & $645 \cdot 8$ & $4 \cdot 8$ & -7 & $<0.01$ \\
\hline Processed foods & $36 \cdot 0$ & $1 \cdot 1$ & 44.9 & 1.5 & $53 \cdot 3$ & 1.6 & 39 & $<0.01$ \\
\hline Ultra-processed foods and drinks & $87 \cdot 1$ & $2 \cdot 7$ & $121 \cdot 1$ & $3 \cdot 3$ & $169 \cdot 8$ & 2.9 & 66 & $<0.01$ \\
\hline \multicolumn{9}{|l|}{ Traditional classification } \\
\hline Beans & $123 \cdot 1$ & $2 \cdot 6$ & $117 \cdot 2$ & $2 \cdot 2$ & $86 \cdot 6$ & 1.7 & -33 & $<0.01$ \\
\hline Vegetables & 11.9 & 0.5 & $20 \cdot 1$ & 0.7 & $30 \cdot 3$ & 0.7 & 89 & $<0.01$ \\
\hline Fruit & $35 \cdot 3$ & 1.6 & $37 \cdot 1$ & 1.3 & $57 \cdot 4$ & 1.6 & 51 & $<0.01$ \\
\hline Milk & $30 \cdot 0$ & 1.6 & $36 \cdot 1$ & 1.5 & $46 \cdot 2$ & 1.5 & 43 & $<0.01$ \\
\hline Sweets & $17 \cdot 3$ & 0.6 & $19 \cdot 8$ & 0.7 & 21.9 & 0.6 & 23 & $<0.01$ \\
\hline Crackers & $4 \cdot 1$ & 0.2 & 3.6 & 0.2 & 3.6 & 0.2 & -13 & 0.11 \\
\hline Snacks & 3.4 & 0.3 & $5 \cdot 7$ & 0.4 & $10 \cdot 3$ & 0.4 & 107 & $<0.01$ \\
\hline Soft drinks & $26 \cdot 7$ & 1.6 & $45 \cdot 3$ & $2 \cdot 1$ & 69.2 & 2.2 & 90 & $<0.01$ \\
\hline
\end{tabular}

*Income tertiles (monthly per capita household): T1, $\leq$ SUS 103.4; T2, > \$US 103.4-223.5; T3, > \$US 223.5. \$US $1=2.38$ Brazilian Real.

†Diff.: difference in percentage between mean food group intake in the third and first tertiles: [(mean in T3 - mean in T1)/general mean] $\times 100$.

fUnprocessed or minimally processed foods + processed culinary ingredients.

Table 3 Income-adjusted weighted mean food group intake (SE) by NOVA and traditional food group classifications according to adolescent individual earnings. Brazil, 2008-2009 National Dietary Survey

\begin{tabular}{|c|c|c|c|c|c|}
\hline \multirow[b]{2}{*}{ Food group ( $\mathrm{g} / \mathrm{kJ}$ or $\mathrm{ml} / \mathrm{kJ})$} & \multicolumn{2}{|c|}{$\begin{array}{l}\text { Adolescent with individual } \\
\text { earnings }(n \text { 1101) }\end{array}$} & \multicolumn{2}{|c|}{$\begin{array}{l}\text { Adolescent without individual } \\
\text { earnings }(n \text { 2572) }\end{array}$} & \multirow[b]{2}{*}{$P$} \\
\hline & Mean & SE & Mean & SE & \\
\hline \multicolumn{6}{|l|}{ NOVA classification } \\
\hline Culinary preparations* & 568.2 & 9.9 & 554.8 & $7 \cdot 8$ & 0.27 \\
\hline Processed foods & 35.9 & $2 \cdot 3$ & 34.8 & 1.2 & 0.67 \\
\hline Ultra-processed foods and drinks & 174.8 & $7 \cdot 3$ & 177.6 & $6 \cdot 1$ & 0.75 \\
\hline \multicolumn{6}{|l|}{ Traditional classification } \\
\hline Beans & $108 \cdot 1$ & 4.4 & $96 \cdot 3$ & $2 \cdot 8$ & 0.02 \\
\hline Vegetables & $13 \cdot 7$ & 1.0 & $12 \cdot 1$ & 0.6 & 0.17 \\
\hline Fruit & 33.5 & $2 \cdot 9$ & $32 \cdot 2$ & 1.8 & 0.71 \\
\hline Milk & 34.2 & 3.0 & $40 \cdot 9$ & $2 \cdot 7$ & 0.09 \\
\hline Sweets & $26 \cdot 2$ & 1.6 & $27 \cdot 2$ & $1 \cdot 2$ & 0.60 \\
\hline Crackers & 3.8 & 0.5 & 4.5 & 0.5 & 0.26 \\
\hline Snacks & $12 \cdot 3$ & 1.5 & $8 \cdot 6$ & 0.6 & 0.02 \\
\hline Soft drinks & $77 \cdot 9$ & 4.9 & $69 \cdot 1$ & $3 \cdot 8$ & 0.15 \\
\hline
\end{tabular}

*Unprocessed or minimally processed foods + processed culinary ingredients.

outside the home ${ }^{(16)}$. Among adolescents, the sale of soft drinks and deep-fried snacks in schools favours the regular consumption (more than 5 times/week) of these items ${ }^{(17)}$.

On the other hand, the consumption of beans and culinary preparations was more frequent in the lowest stratum of family income. Brazilian studies have shown that diets based on traditional Brazilian foods, characterized by rice, beans and some culinary preparations, are more frequent among adolescents ${ }^{(18)}$ and households ${ }^{(19,20)}$ with lower socio-economic status. Even with adjustment for household income, bean intake was higher among adolescents with individual earnings compared with those without individual earnings, also indicating that individual earnings may be related to adolescent jobs. Hence, our findings suggest that although adolescents with individual income consume more snacks, they also consume items of the traditional Brazilian diet.
Except for snack and bean intakes, we observed no difference in food group intakes according to adolescents' individual earnings. This may indicate that adolescents did not spend their own income on food acquisition. Moreover, adolescents with individual earnings, mainly males, had lower per capita household income, indicating that they probably work and receive money to complement family earnings. Therefore, our results suggest that differences in food consumption were more influenced by family income than adolescents' individual earnings.

Family diet seems to have an important role in diet adherence during childhood and adolescence ${ }^{(21)}$ and parental socio-economic status has a direct effect on diet quality ${ }^{(22)}$. Barufaldi et $a l^{(23)}$ found higher prevalence of meal consumption with parents or guardians among adolescents from high socio-economic families (mothers with high level of schooling). In our study, a mosaic of healthy and unhealthy items characterized adolescents' 
diet in the highest family income level. While the difference in food intake between extreme tertiles of household income was $90 \%$ for soft drinks and $66 \%$ for ultraprocessed foods, we observed $89 \%$ for vegetables and $51 \%$ for fruit, both with highest intake among the highest income stratum.

In Brazil, the inclusion of fruit and vegetables in the family diet is strongly influenced by household income and food price. Claro et al. ${ }^{(24)}$ observed an increase of $0.04 \%$ and $0.2 \%$ in the participation of fruit and vegetables in total energy content with an increase of $1 \%$ in family income and a decrease of $1 \%$ in the price of fruit and vegetables, respectively. On the other hand, Claro et al. ${ }^{(25)}$ demonstrated that the cost of unprocessed or minimally processed foods and processed culinary ingredients, here named 'culinary preparations', was lower than the cost of ultra-processed foods. Hence, a high household availability of healthy food groups does not represent low availability of unhealthy food groups ${ }^{(26)}$.

In addition, the overweight and obesity prevalence of Brazilian adolescents is higher among those in the highest per capita household income level, mainly among males $^{(3)}$. A poor diet quality with high intakes of sweets and caloric beverages ${ }^{(27)}$ is associated with increasing risk of obesity among children and adolescents ${ }^{(27-31)}$. This is particularly worrisome among adolescents due to the consequences of being overweight later in life ${ }^{(32)}$.

Adolescents with pocket money usually increase their autonomy to pay for a variety of goods, including food ${ }^{(33)}$. This practice seems to have a positive correlation with income level, visits to fast-food restaurants and unhealthy eating ${ }^{(34-36)}$. However, to our knowledge, no study has evaluated specifically the receipt of pocket money and the relationships with food habits in low- and middle-income countries. In general, purchase of food for out-of-home consumption is positively associated with income among Brazilian families ${ }^{(37)}$.

In our study, it is not possible to distinguish whether the adolescent individual earnings were from pocket money or formal or informal work. Since the family income of adolescents with individual earnings is lower than that of their counterparts, it suggests that these earnings come from adolescents' jobs. Also, we cannot estimate whether their individual income was spent on food purchasing or whether the food bought was consumed inside or outside the home.

Another limitation of the present study is the dietary intake assessment method used. Food records may be subject to errors related to dietary change on the day of report and errors in detailing food consumed. Trained interviewers advised individuals on how to fill in the food records and checked the reported information in the individual's home following standard instructions. Pictures of tableware helped to minimize errors related to report of quantity food intake.

Regarding the use of NOVA classification, the lack of association with adolescent earnings may be due to the required precise definitions of the types of food processing of each dietary food group. For example, milk without any other ingredient is included in the group of culinary preparations, while yoghurt or flavoured milk, such as common chocolate milk, is an ultra-processed food item. This detailed nutritional information cannot always be obtained in nationwide studies. This method requires details on the source of the food item used in preparations, dishes and meals; for instance, if the preparation was made from scratch or bought prepared or semi-prepared. Another example is the classification of juices; it is necessary to know if the juice was prepared from fresh fruit, frozen fruit or if it was already prepared in a box juice or made from powdered flavouring. The detailed information on food consumption often becomes impractical considering the logistics required to collect national data, involving many limitations, mainly related to cost and time spent on interviews.

To our knowledge, the present study is the first that evaluated the impact of adolescents' individual earnings on food intake in Brazil. Our data indicate that family income, more than individual financial autonomy, is the main driver of quality of food choices among Brazilian adolescents. Strategies that aim to improve the food choices of adolescents should focus on nutritional interventions for the whole family while taking account of family food access.

\section{Acknowledgements}

Financial support: This research received no specific grant from any funding agency in the public, commercial or notfor-profit sectors. Conflict of interest: None of the authors has conflicts of interest. Authorship: M.C.A., D.B.C., I.N.B. and R.S. contributed to the design of the study, analysis and interpretation of the data, and the drafting of the manuscript; M.B.T.d.C. contributed to the interpretation of the data and the drafting of the manuscript. All authors read and approved the final manuscript. Ethics of human subject participation: This study was conducted according to the guidelines laid down in the Declaration of Helsinki and all procedures involving human subjects/patients were approved by the internal research board at the University of the State of Rio de Janeiro (CAAE 0011.0.259.000-11).

\section{References}

1. Souza A de M, Barufaldi LA, Abreu G de A et al. (2016) ERICA: intake of macro and micronutrients of Brazilian adolescents. Rev Saude Publica 50, Suppl. 1, 5 S.

2. Veiga GV, Costa RS, Araújo MC et al. (2013) Inadequate nutrient intake in Brazilian adolescents. Rev Saude Publica 47, Suppl. 1, 212S-221S.

3. Instituto Brasileiro de Geografia e Estatística (2010) Pesquisa de Orçamentos Familiares no Brasil, 2008-2009. Antropometria e Análise do Estado Nutricional de Crianças 
e Adolescents no Brasil (Household Expenditure Survey in Brazil, 2008-2009. Anthropometry and Analysis of the Nutritional Status of Children and Adolescents in Brazil). Rio de Janeiro: IBGE and Ministério do Planejamento, Orçamento e Gestão.

4. Harriger JA \& Thompson JK (2012) Psychological consequences of obesity: weight bias and body image in overweight and obese youth. Int Rev Psychiatry 24, 247-253.

5. Duarte CS, Sourander A, Nikolakaros G et al. (2010) Child mental health problems and obesity in early adulthood. J Pediatr 156, 93-97.

6. BeLue R, Francis LA \& Colaco B (2009) Mental health problems and overweight in a nationally representative sample of adolescents: effects of race and ethnicity. Pediatrics $\mathbf{1 2 3}$, 697-702.

7. DiClemente RJ, Hansen WB \& Ponton LE (1996) Adolescents at risk. In Handbook of Adolescent Health Risk Behavior, pp. 1-4 [RJ DiClemente, WB Hansen and LE Ponton, editors]. New York: Plenum Press.

8. Steinberg L (2001) We know some things: parent-adolescent relationships in retrospect and prospect. J Res Adolesc 11, 1-19.

9. Story M, Neumark-Sztainer D \& French S (2002) Individual and environmental influences on adolescent eating behaviors. J Am Diet Assoc 102, 3 Suppl., S40-S51.

10. Wang Y, Beydoun M, Li J et al. (2011) Do children and their parents eat a similar diet? Resemblance in child and parental dietary intake - systematic review and meta-analysis. J Epidemiol Community Health 65, 177-189.

11. Veiga GV da \& Sichieri R (2006) Correlation in food intake between parents and adolescents depends on socioeconomic level. Nutr Res 26, 517-523.

12. Instituto Brasileiro de Geografia e Estatística (2011) Pesquisa de Orçamentos Familiares, 2008-2009. Análise do Consumo Alimentar Pessoal no Brasil (Housebold Expenditure Survey 2008-2009. Analysis of the Personal Food Consumption in Brazil). Rio de Janeiro: IBGE and Ministério do Planejamento, Orçamento e Gestão.

13. World Health Organization (2007) WHO growth reference data for 5-19 years. http://www.who.int/growthref/tools/ en/ (accessed May 2016).

14. Ministry of Health of Brazil, Secretariat of Health Care, Primary Health Care Department (2014) Dietary Guidelines for the Brazilian Population. Brasilia: Ministry of Health of Brazil.

15. Monteiro CA, Cannon G, Levy RB et al. (2016) NOVA. The star shines bright. Food classification. Public Health. World Nutrition 7, 28-38.

16. Bezerra IN, Souza A de M, Pereira RA et al. (2013) Consumption of foods away from home in Brazil. Rev Saude Publica 47, Suppl. 1, 200S-211S.

17. Azeredo CM, Rezende LFM, Canella DS et al. (2016) Food environments in schools and in the immediate vicinity are associated with unhealthy food consumption among Brazilian adolescentes. Prev Med 88, 73-79.

18. Rodrigues PR, Pereira RA, Cunha DB et al. (2012) Factors associated with dietary patterns in adolescents: a schoolbased study in Cuiabá, Mato Grosso. Rev Bras Epidemiol 15, 662-674.

19. Arruda SP, da Silva AA, Kac G et al. (2014) Socioeconomic and demographic factors are associated with dietary patterns in a cohort of young Brazilian adults. BMC Public Health 26, 654 .
20. Marchioni DM, Claro RM, Levy RB et al. (2011) Patterns of food acquisition in Brazilian households and associated factors: a population-based survey. Public Health Nutr 14 , 1586-1592.

21. Emmett PM, Jones LR \& Northstone K (2015) Dietary patterns in the Avon Longitudinal Study of Parents and Children. Nutr Rev 73, 207-230.

22. Béghin L, Dauchet L, De Vriendt T et al. (2013) Influence of parental socio-economic status on diet quality of European adolescents: results from the HELENA study. Br J Nutr 111, 1303-1312.

23. Barufaldi LA, Abreu G de A, Oliveira JS et al. (2016) ERICA: prevalence of healthy eating habits among Brazilian adolescents. Rev Saude Publica 50, Suppl. 1, 6s.

24. Claro RM, Carmo HCE, Machado FMS et al. (2007) Income, food prices, and participation of fruits and vegetables in the diet. Rev Saude Publica 41, 557-564.

25. Claro RM, Maia EG, Costa BV et al. (2016) Food prices in Brazil: prefer cooking to ultra-processed foods. Cad Saude Publica 32, e00104715.

26. Bezerra IN \& Sichieri R (2011) Household food diversity and nutritional status among adults in Brazil. Int J Behav Nutr Phys Act 8, 22.

27. Torre SBD, Keller A, Depeyere JL et al. (2016) Sugarsweetened beverages and obesity risk in children and adolescents: a systematic analysis on how methodological quality may influence conclusions. J Acad Nutr Diet 116, 638-659.

28. Rosenheck R (2008) Fast food consumption and increased caloric intake: a systematic review of a trajectory towards weight gain and obesity risk. Obes Rev 9, 535-547.

29. Collison KS, Zaidi MZ, Subhani SN et al. (2010) Sugarsweetened carbonated beverage consumption correlates with BMI, waist circumference, and poor dietary choices in school children. BMC Public Health 10, 234.

30. Almuhanna MA, Alsaif M, Alsaadi M et al. (2014) Fast food intake and prevalence of obesity in school children in Riyadh City. Sudan J Paediatr 14, 71-80.

31. Canella DS, Levy RB, Martins APB et al. (2014) Ultraprocessed food products and obesity in Brazilian households (2008-2009). PLoS One 9, e92752.

32. Gurnani M, Birken C \& Hamilton J (2015) Childhood obesity causes, consequences, and management. Pediatr Clin North Am 62, 821-840.

33. Li M, Xue H, Jia P et al. (2017) Pocket money, eating behaviors, and weight status among Chinese children: the Childhood Obesity Study in China mega-cities. Prev Med 100, 208-215.

34. Punitha VC, Amudhan A, Sivaprakasam P et al. (2014) Pocket money: influence on body mass index and dental caries among urban adolescents. J Clin Diagn Res 8, 10-12.

35. Roberts BP, Blinkhorn AS \& Duxbury JT (2003) The power of children over adults when obtaining sweet snacks. Int $J$ Paediatr Dent 13, 76-84.

36. Jensen JD, Bere E, de Bourdeaudhuij I et al. (2012) Microlevel economic factors and incentives in children's energy balance related behaviours - findings from the ENERGY European cross-section questionnaire survey. Int J Behav Nutr Phys Act 9, 136.

37. Claro RM, Levy RB \& Bandoni DH (2009) Influence of income on food expenditures away from home among Brazilian families, 2002-2003. Cad Saude Publica 25, 2489-2496. 